\title{
Density, Viscosity and Ultrasonic Velocity of Polyethylene Glycol
}

\author{
Richa Saxena $^{1^{*}} \cdot \mathrm{SC}$ Bhatt $^{2} \cdot$ Manish Uniyal $^{2} \cdot \mathrm{S} \mathrm{C}$ Nautiyal $^{3}$ \\ ${ }^{1}$ IFTM University, Lodhipur, Rajput, Moradabad 244001, India \\ ${ }^{2}$ Department of Physics, H N B Garhwal University Srinagar (Garhwal) 246174, India \\ ${ }^{3}$ Department of Physics, Govt. P.G. College, Raipur, Dehradun, Uttarakhand, India
}

*Corresponding Author Email: saxena.richa23@gmail.com

Received: 2.8.2021; Revised : 23.9.2021; Accepted: 26.9.2021

(O) Society for Himalayan Action Research and Development

\begin{abstract}
Ultrasonic velocity, density, and viscosity of polyethylene glycol have been measured for the solution in water at concentration range of $0.3 \%$ to $1 \%$ at temperature $50^{\circ} \mathrm{C}$. Ultrasonic velocity has been measured using ultrasonic interferometer at $1 \mathrm{MHz}$ frequency. By using the values of ultrasonic velocity, density, and viscosity, various acoustical parameters like adiabatic compressibility, acoustic impedance, intermolecular free length, and relaxation time have been calculated. The change in these acoustical parameters is explained in terms of solutesolvent interaction in a polymer solution.
\end{abstract}

Keywords: Density, Viscosity, Ultrasonic Velocity, Pplyethylene Glycol

\section{Introduction}

In recent years, ultrasonic velocity measurement has been employed in understanding the molecular interaction in pure liquids and liquid mixtures. The ultrasonic velocity measurements are very useful to provide information about strength of molecular interaction and physical nature of solute and solvents (Mehta and Chauhan 1997, Dewan et al 1991). Ultrasonic velocity of a liquid is fundamentally related to the binding forces between the atoms of the molecules and has been adequately employed in understanding the nature of molecular interaction in pure liquids(Tabhane 1983, Srinivasalu and Naidu Ranachandra 1991,
Kannappan and Rajendran 1991).Polyethyleneglycol finds enormous use in the field of microbiology, biochemistry, drug delivery, gas chromatography and pharmaceutical industry (Nagara and Yamamoto 2008, Pittini et al 2008). Polymer dissolution also plays a key role in many industrial applications in variety of areas and an understanding of the dissolution process allows for the optimization of design and processing conditions as well as selection of suitable solvents. Aqueous solutions play a vital role for many geological processes in various environments, such as geothermal and magmatic hydrothermal settings. Subramanian Ravichandran et al. (2011) studied the 
ultrasonic studies on molecular interactions in the binary mixture of ammonium chloride in Polyethylene glycol solution. They reported the theoretical values of ultrasonic velocity in binary liquid mixture. Syal et al (2005) studied the ultrasonic velocity, density and ultrasonic velocity of Polyethylene glycols(PEG800,PEG-20,000) in acetonitrile and water mixtures at $25^{\circ} \mathrm{C}$ and they concluded that acetonitrile acts as a structure breaker in AN+ $\mathrm{H} 2 \mathrm{O}$ solvent system releasing more water dipoles to interact at oxygen sites of PEG chains. Some of the researchers studied the ultrasonic characteristics of aqueous solution of Polyehtlene glycol (Venkata Ramana 2005, Kalyana and Hemalatha 1999, Lalitha et al 1996).Very few studies are available on aqueous solution of Polyethyleneglycol. Because of wide use of this liquid is chosen in present investigations ${ }^{13}$

\section{Experimental details}

In the present investigation polyethyleneglycol of molecular weight approximately (200 Da) in liquid form is used. The solutions were prepared by adding known weight of polyethyleneglycol in fixed volume of water and stirring, until a clear solution was formed. The concentration studied have been done with solution of concentration $1.0 \%, 0.8 \%$, $0.6 \%, 0.5 \%, 0.4 \%, 0.3 \%(\mathrm{v} / \mathrm{v})$. Acoustical parameters like adiabatic compressibility, acoustic impedance, intermolecular free length, and relaxation time have been calculated at $50^{\circ} \mathrm{C}$ temperature and at $1.0 \%, 0.8 \%, 0.6 \%, 0.5 \%, 0.4 \%, 0.3 \%$

concentration at $1 \mathrm{MHz}$ frequency. The ultrasonic velocity is measured by using ultrasonic interferometer with accuracy of $\pm 0.4 \mathrm{~m} / \mathrm{s}$ at $35^{\circ} \mathrm{C}$. The temperature of the solution has been kept constant. The density at different temperature is also measured. The accuracy in density measurements was about $0.5 \mathrm{~kg} / \mathrm{m}^{3}$. The viscosity of the mixtures was also determined at constant temperature. The accuracy in the viscosity measurements is within $\pm 0.5 \%$. These parameters are calculated by using standard relations (Saxena and Bhatt 2010, Saxena et al 2020, Saxena and Bhatt 2018).

\section{Result and Discussion}

In present investigation density, viscosity and ultrasonic velocity have been measured at $1.0 \%, 0.8 \%, 0.6 \%, 0.5 \%, 0.4 \%, 0.3 \% \quad(\mathrm{v} / \mathrm{v}) \quad$ at $50^{\circ} \mathrm{C}$ concentration at $1 \mathrm{MHz}$ frequency. Using these values different acoustical parameters adiabatic compressibility, acoustic impedance, intermolecular free length and relaxation time has been calculated for aqueous solution of Polyethylene glycol at $1.0 \%, 0.8 \%, 0.6 \%$, $0.5 \%, 0.4 \%, 0.3 \%$ concentration and at $50^{\circ} \mathrm{C}$ temperature have been presented in Table 1, 2, 3,4,5,6 and 7 respectively. Table- 1 and Fig 1 represents the variation of density of polyethylene glycol with concentration at $50^{\circ} \mathrm{C}$. It is clear from Fig 1 that density increases with increase in concentration. The results are in good agreement with previous reports (Selvakumar and Krishna 2008). Viscosity is one of the important property of liquid. It is dependent on its molecular size, shape and intermolecular interaction. Some acoustical parameters also depend on 
viscosity. Table-2 and Fig-2 shows that viscosity increases with increase in concentration of PEG-200 this may be due to shrinkage in the volume because of presence of solute molecules. This results in more frictional force that is developed between the layers of the solution. The increasing trend of viscosity with concentration revealed that the addition of a polymer increases the effective molecular area. The trends are in agreement with the results of earlier researchers (Fabio et al 2000). Ultrasonic velocity increases with increase in concentration of PEG in the solution (Table3, Figure 3). Velocity studies show that as the polymer concentration increases a more rigid molecular structure is formed perhaps by bonding between the large polymer molecules. The variation of ultrasonic velocity in a mixture depends upon increase or decrease of intermolecular free length after mixing components. On the basis of a model, for sound propogation proposed by Eyring and Kincaid (Erything and Kincaid 1938), ultrasonic velocity should decrease, if the intermolecular free length increase and viceversa. This is in fact observed in the present investigation. It is observed that with increase in concentration of polyethylene glycol in solution, the adiabatic compressibility decreases (Table 4 and Fig 4). This shows the enhancement of the bond strength with concentration. Similar results are reported in earlier reported data (Jayakumar et al 2015). Variation of acoustic impedance with temperature is shown in (Table 5 and Fig.5). It is noticed that the acoustic impedance increases with increasing concentration. These results also support the conclusions drawn from the behaviour of variation in ultrasonic velocity. This is in agreement with the requirement as both ultrasonic velocity and density increase with increase in concentration of the solute and also effective due to solutesolvent interactions (Syal et al 2005). Change of intermolecular free length with concentration is presented in Table - 6 and Fig. 6 which shows that with increase in concentration of PEG in solution, it decreases. This is also in accordance with the expected molecular interaction between the solutesolvent, increases in compressibility. The results are in good agreement with earlier reported data (Thirumaran et al 2013).Table 7 and Fig. 7 show the variation of relaxation time with concentration. It is clearly seen that relaxation time decreases with increase in concentration of Polyethylene glycol. This may be due to structural relaxation process.

\section{Conclusion}

The present study shows that there exist a strong interaction between solute and solvent. It is also concluded that association between Polyethylene glycol and water is responsible for increase in ultrasonic velocity. This in turn affects other acoustical parameters. It may be due to Polymer molecules come to the solvent molecules leaving sufficient space around them. The result also indicate the existence of positive interactions between polymer and molecules 
Table: 1- Density $\left(x_{10} \mathrm{~kg}^{3} \mathrm{~m}^{3}\right)$ of polyethylene glycol (PEG) at different concentration and at $5^{0} \mathrm{C}$ temperature at $1 \mathrm{MHz}$ frequency-

\begin{tabular}{cc}
\hline Concentration & Density \\
\hline $1 \%$ & 1.506 \\
$0.8 \%$ & 1.412 \\
$0.6 \%$ & 0.966 \\
$0.5 \%$ & 0.915 \\
$0.4 \%$ & 0.970 \\
$0.3 \%$ & 0.969 \\
\hline
\end{tabular}

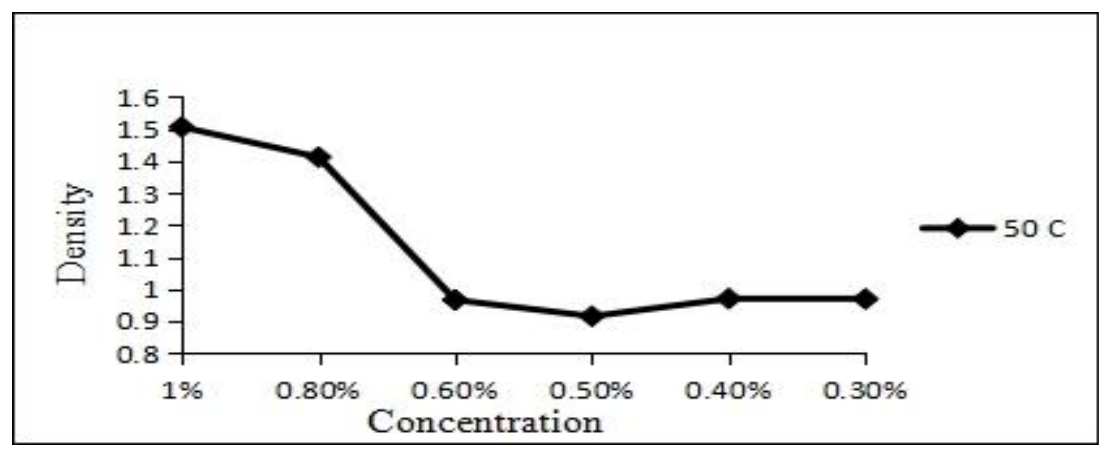

Fig.-1: Variation of density with concentration at $50^{\circ} \mathrm{C}$ temperature

Table: 2-Viscosity $\left(\mathrm{x10}^{-1} \mathrm{~Pa} . \mathrm{sec}\right)$ of polyethylene glycol (PEG) at different concentration and at $50^{0} \mathrm{C}$ temperature at $1 \mathrm{MHz}$ frequency-

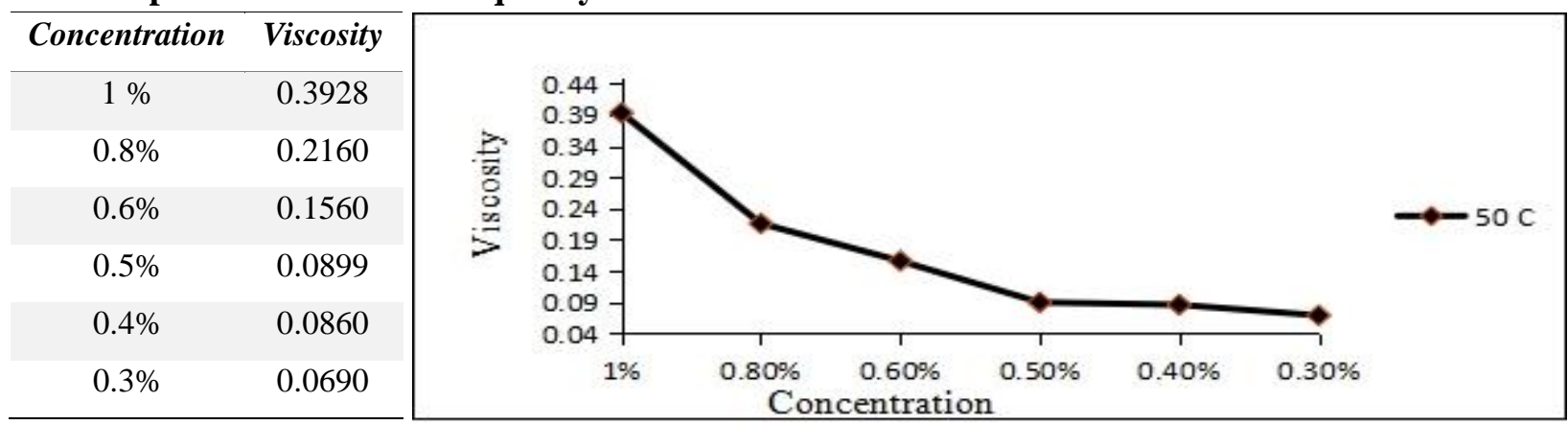

Fig.-2: Variation of viscosity with concentration at $50^{\circ} \mathrm{C}$ temperature

Table: 3-Ultransonic velocity (m/s) of polyethylene glycol (PEG) at different concentration and at $50^{\circ} \mathrm{C}$ temperature $1 \mathrm{MHz}$ frequency

\begin{tabular}{cc}
\hline Concentration & Ultrasonic velocity \\
\hline $1 \%$ & 1605.8 \\
$0.8 \%$ & 1595.4 \\
$0.6 \%$ & 1585.9 \\
$0.5 \%$ & 1574.9 \\
$0.4 \%$ & 1563.6 \\
$0.3 \%$ & 1562.7 \\
\hline
\end{tabular}

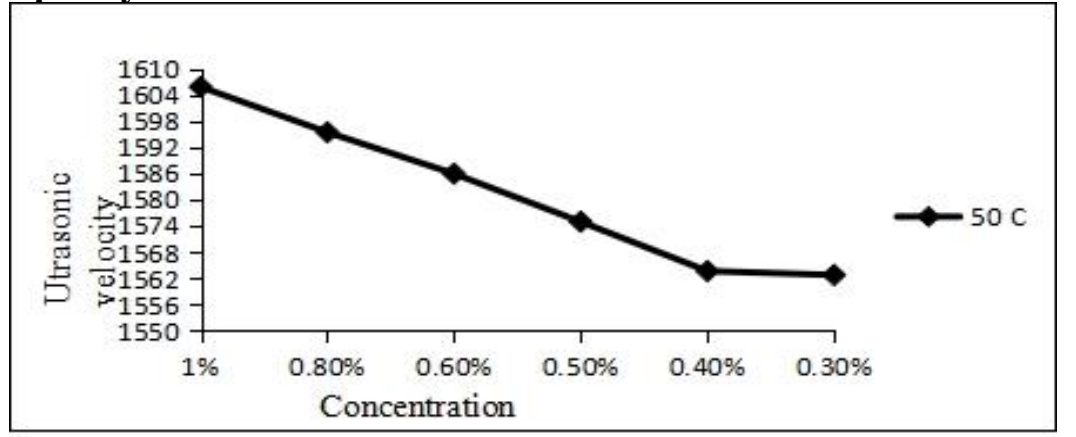

Fig.-3: Variation of ultrasonic velocity with concentration at $50^{\circ} \mathrm{C}$ temperature 
Table: 4- Adiabatic compressibility $\left(x_{10}{ }^{-10} \mathrm{~kg}^{-1} \mathrm{~ms}^{2}\right)$ at different concentration and at $50^{0} \mathrm{C}$ temperature at $1 \mathrm{MHz}$ for polyethylene glycol (PEG)-

\begin{tabular}{cc}
\hline Concentration & Adiabatic compressibility \\
\hline $1 \%$ & 2.574 \\
$0.8 \%$ & 2.783 \\
$0.6 \%$ & 4.116 \\
$0.5 \%$ & 4.407 \\
$0.4 \%$ & 4.215 \\
$0.3 \%$ & 4.226 \\
\hline
\end{tabular}

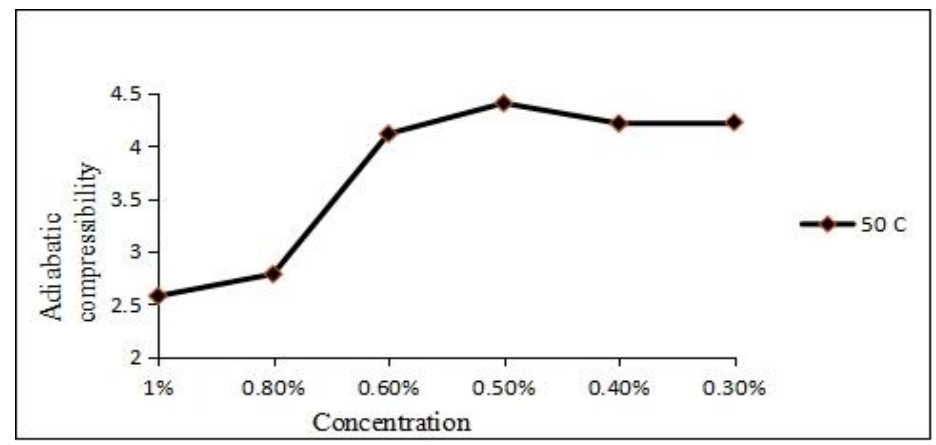

Fig.-4: Variation of adiabatic compressibility with concentration at $50^{\circ} \mathrm{C}$ temperature

Table: 5- Acoustic impedance $\left(\mathrm{x10}^{3} \mathrm{kgm}^{2} \mathrm{~s}^{-1}\right)$ at different concentration at $50^{0} \mathrm{C}$ temperature at $1 \mathrm{MHz}$ for polyethylene glycol (PEG)-

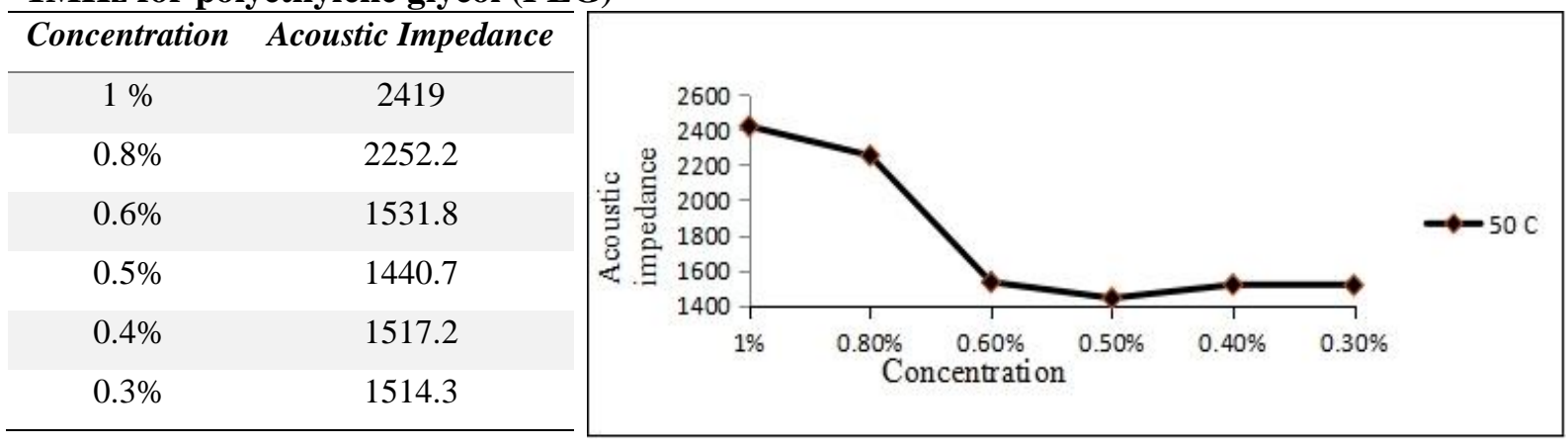

Fig.- 5: Variation of Acoustic Impedance with concentration at $50^{\circ} \mathrm{C}$ temperature

Table: 6- Intermolecular Free Length $\left(\mathrm{x10}^{-13} \mathrm{~m}\right)$ at different concentration a $50^{0} \mathrm{C}$ temperature at $1 \mathrm{MHz}$ for polyethylene glycol (PEG)-

\begin{tabular}{cc}
\hline Concentration & Intermolecular free length \\
\hline $1 \%$ & 2.172 \\
$0.8 \%$ & 2.258 \\
$0.6 \%$ & 2.746 \\
$0.5 \%$ & 2.841 \\
$0.4 \%$ & 2.79 \\
$0.3 \%$ & 2.782 \\
\hline
\end{tabular}

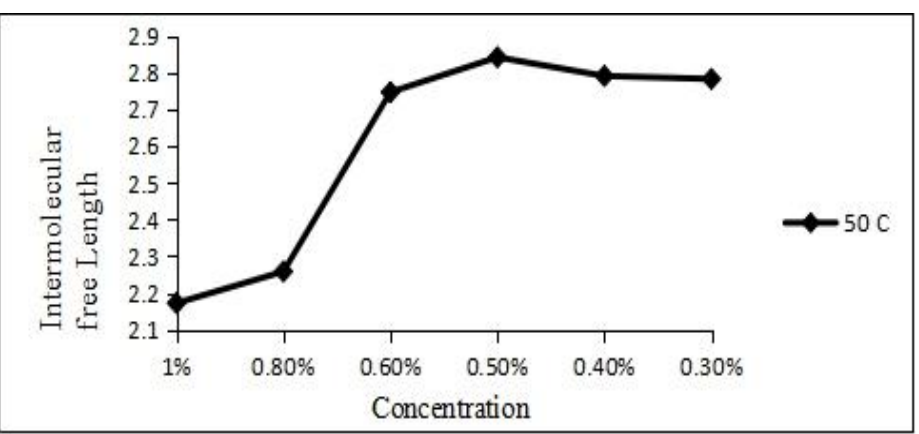

Fig.- 6: Variation of Intermolecular free Length with concentration at $50^{\circ} \mathrm{C}$ temperature 
Table: 7 - Relaxation time $\left(\mathrm{x10}^{-12} \mathrm{~s}\right)$ at different concentration at $50^{\circ} \mathrm{C}$ temperature at $1 \mathrm{MHz}$ for polyethylene glycol (PEG)-

\begin{tabular}{cc}
\hline Concentration & Relaxation Time \\
\hline $1 \%$ & 1.35 \\
$0.8 \%$ & 0.868 \\
$0.6 \%$ & 0.856 \\
$0.5 \%$ & 0.528 \\
$0.4 \%$ & 0.483 \\
$0.3 \%$ & 0.389
\end{tabular}

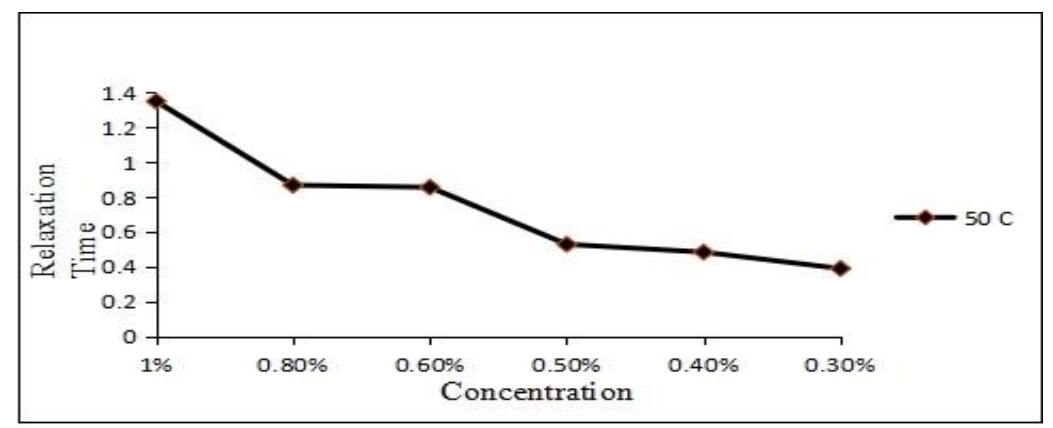

Fig.- 7: Variation of Relaxation time with concentration at $50^{\circ} \mathrm{C}$ temperature

\section{References}

AM C Beth and Jack L K, Polym Sci,(2003) 28:1223.

Dewan RK, Mehta SK, Parashar R and Bala K (1991) Topological investigations on the association of alkanols: excess volume of pyridine-alkanol $\left(\mathrm{C}_{1}-\mathrm{C}_{10}\right)$ mixtures, $\mathrm{J}$. Chem. Soc. Faraday Trans, 87:1561.

Erything HJ and Kincaid JF (1938) Free Volumes and Free Angle Ratios of Molecules in Liquids, J. Chem. Phys. (USA) 6: 62.

Fabio Comelli, Adriana Bigi, Daniele Vitalini, and Katia Rubini (2000) Densities, Viscosities, Refractive Indices, and Heat Capacities of Four Poly(ethylene glycol)-Poly(propyleneglycol)-Poly(ethy leneglycol)- block Copolymers + Dimethyl Sulfoxide at (298.15 and 313.15) K and at Atmospheric Pressure, J. Chem. Eng. Data, 30:20.
Jayakumar S, George Mary Preetha, Shubhashshree NS, Divya P, Anees Ahmed M (2015) International $\mathbf{J}$ of Innovative Research in Science, Engineering and Technology, 4: 112.

Kalyana Sundaram S, Hemalatha J (1999) J. Acoust.Soc. Ind., 27: 389.

Kannappan AN and Rajendran V (1991) Molecular interaction studies in ternary liquid mixtures from ultrasonic data, Indian $\mathbf{J}$ of Pure and Applied Physics, 29, 465.

Lalitha Sri, Subha MCS, Chowdoji Rao K(1996) Ind. J. Pure.Appl.Ultrason., 18: 59.

Mehta SK and Chauhan RK (1997), Ultrasonic velocity and apparent isentropic compressibilities in mixtures of nonelectrolytes, J of Solution Chemistry, 26: 295 .

Nagara M and Yamamoto Y (2008) Reactive Functional Polymer, 68:915. 
Pittini Y, Daneshvari D, Pittini R, Vaucher S, Rohr L, Leparoux S and Leuenberger $\mathrm{H}$ (2008) Cole- Cole plot analysis of dielectric behavior of monoalkyl ethers of polyethylene glycol $(\mathrm{CnEm}), \quad$ Eur Polym J, 44:1191.

Ravichandran Subramanian, Ramanathan K(2011) Ultrasonic studies on molecular interactions in the binary mixture of ammonium chloride in polyethylene glycol (600) solution Physical

Chemistry An Indian Journal, vol 6(1):59-64.

Saxena R and Bhatt SC (2010) "Molecular Interactions in Binary mixture of Polymethylmethacrylate with Acetic Acid, International Journal of Chemistry, 2:164.

Saxena R, Bhatt SC, Uniyal Manish \& Nautiyal SC, Density, viscosity and ultrasonic study of polymethylmethacrylate, Applied Innovative Research Vol. 2, March (2020)36-38.

Saxena Richa and Bhatt SC (2018) Molecular Association Studies on Polyvinyl Alcohol at different Concentrations, Advances in Materials Science and Engineering, Volume 2018, Article ID 17386, 12:1- 5 .

Selvakumar M and Krishna Bhat D(2008) Molecular interactions of polymethyl methacrylate and polyethylene solutions in tetrahydrofuran, Indian $\mathbf{J}$ of Pure and Applied Physics, 46:712-718.
Srinivasalu U and Naidu Ranachandra P(1991) Indian J. Pure and Applied Physics, 29:576.

Syal VK, Chauhan Anita, Chauhan Suvarcha (2005) Ultrasonic velocity, viscosity and density studies of poly (ethylene glycols) (PEG - 8,000, PEG - 20,000) in acetonitrile (AN) and water $(\mathrm{H} 2 \mathrm{O})$ mixtures at 250C J. Pure. Appl. Ultrasonics., 27: 61-69.

Tabhane VA (1983) Acoustical Lett.(GB) $6: 120$

Thirumaran S, George Gene, Vijay S, and Prakash N(2013), Acoustical and thermodynamical studies of molecular interactions in aqueous ethylene glycol at $303.15, \quad 308.15$ and $313.15 \mathrm{~K}$, International $\mathbf{J}$ of Pharmaceutical, Chemical and Biological Sciences, 3:488494.

Venkata Ramana G, E.Raja Gopal., Manahara Moorthy N (2005) J.Pure.Appl.Ultrason., 25:33. 